\title{
CAN CONTINUOUS, INTER-GENERATIONAL COOPERATION POSITIVELY IMPACT THE QUALITY OF LIFE OF ELDERLY ALZHEIMER'S SUFFERERS?: AN INTERIM REPORT
}

\author{
R. Rokkaku1, A. Homma², S. Kobayashi', Y. Seki
}

\begin{abstract}
This article summarizes the impact of inter-generational cooperation on the quality of life of elderly Alzheimer's sufferers. The study is a continuing, two-year intervention and reports the results of the first year. It consists of an intervention and a control group of eight and six sufferers, respectively, who have been diagnosed with Alzheimer's disease. Both groups attend day care services. The intervention group participates in the inter-generational program with children, while the control group does not. On the Philadelphia Geriatric Center Affect Rating Scale, three items have been proved statistically significant. Pleasure, Interest, and Contentment have increased with inter-generational cooperation. The magnitude of the change was not so remarkable as to influence QOL-AD at home. However, the present results may imply a reduction on the burden of the day care service staff and family carers. Another advantage may be in the educating of the children's parents, whose understanding of dementia was poor.
\end{abstract}

Key words: Inter-generational cooperation, Alzheimer's sufferers, children, quality of life.

\section{Introduction}

In Japan over recent years, a rising number of nuclear family households means fewer children live with elderly relatives. Between 1975 and 2010, the ratio of threegeneration households, those with a head-of-household 65 years or older, relative to all other types of households, has steadily fallen from 11.8 to $6.9 \%$ (1). Therefore, interaction between children and senior citizens has been decreasing. Moreover, it seems that socio-economic conditions have changed in Japan, requiring young adults to relocate for work. This creates various problems that the elderly generation traditionally provides, such as emotional support, mentoring, babysitting services, and the teaching of customs to the youth generation.

Although a few results have been reported on the intergenerational program between the elderly persons and children, no results have been reported on the intergenerational cooperation between elderly persons with Alzheimer's disease and children. An aim of the present study is to clarify the effect of an inter-generational program for Alzheimer's sufferers through the

1. Tokyo University of Technology, Tokyo, Japan; 2. Dementia care training / study Tokyo center, Japan.

Corresponding Author: R. Rokkaku, School of Health Sciences, Department of Nursing, Tokyo University of Technology, 5-23-22 Nishikamata, Ohta-ku, Tokyo 144-8535, Japan, rokkaku@stf.teu.ac.jp, Tel +81 3-6424-2196

Received July 8, 2014

Accepted for publication August 20, 2014 cooperation with children. This is an interim report of the results of the first year of a continuing, two-year intervention from June 2012 to June 2014.

\section{Subjects}

The subjects of the study consist of the intervention group of eight Alzheimer's sufferers and six Alzheimer's sufferers for the control group, all of whom have been diagnosed with dementia of the Alzheimer's type, based on the diagnostic criteria of DSM-IV-TR (2). Informed consent to participate in the study was obtained from the participants themselves, their carers, and the parents of the children. The intervention group attends day care services at one site in city A and participates in an intergenerational program with children. The control group attends services at another site, also in city A, and is not given the opportunity to interact with children. Both sites are operated by the same organization and the care staff of the both sites rotates at regular intervals to minimize the difference of care. Also, the condition of formal care services is strictly defined by the Long-Term Care Insurance Law in Japan. 


\section{Methods}

The program consists of activities held every morning from 10 to 11:30, with such traditional crafts as making paper fans, carp streamers, rice cakes, toys, and dolls, singing traditional songs, and playing traditional games. All activities are planned one month in advance with the requirements that they are fun, easy-to-do, continuous and varied. The care staff are all nationally licensed nurses, care workers, care helpers, or nursery school teachers.

Assessment are made every six months using the following scales: FAST (Functional Assessment Staging) (3) to measure severity of dementia, HDS-R (Hasegawa's Dementia Scale, revised) (4) which is similar to MMSE and the most common simple psychometric scale in Japan, DAD (Disability Assessment for Dementia) (5) to measure ADL (activities of daily living), Behave-AD (Behavioral Pathology in Alzheimer's Disease) (6) to measure behavioral complications, PGC-ARS (Philadelphia Geriatric Center-Affect Rating Scale) (7) to measure the status of the mood, and QOL-AD (Quality of Life in Alzheimer's Disease) (8) to measure quality of life. A nurse administered HDS-R and evaluated FAST, DAD, Behave-AD, and QOL-AD based on the information of family carers. Also, the same nurse assessed PGC-ARS from the facial expressions and behaviors of the subjects.

In the analysis, the total scores of six scales were analyzed by analysis of variance between the groups. The main effects between the groups, interacting effects by time and the group and the items of DAD, Behave-AD, PGC-ARS and QOL-AD were also analyzed.

\section{Results}

Eight subjects of the intervened group and six subjects of the control group were assessed after 12 months. The demographics of the subjects, including mean age, severity of dementia, HDS-R scores, DAD, Behave-AD and QOL-AD, at the baseline and twelve months of the intervened group and the control group are shown in Table 1. No significant differences were found at the baseline between the intervention and the control groups. In the results of analysis of variance, no significant main effects of the group were found in the scores of FAST, HDS-R, DAD, Behave-AD and QOL-AD between the two groups. As to PGC-ARS, six items of the scale were separately analyzed. Although no significant main effect of the group were not found in the six items, significant interactive effects by the group and time were obtained in the items of pleasure $(\mathrm{F}(1,13)=12.696(\mathrm{p}<0.001))$, interest $(\mathrm{F}(1,13)=5.793(\mathrm{p}<0.05))$, and contentment $(\mathrm{F}(1,13)$ $=5.753(\mathrm{p}<0.05))($ Table 2, Fig. 1, Fig. 2).

In addition, although quantitative results are not available, understanding of dementia in the parents of the children participated in the study was increased through the cooperation with Alzheimer's sufferers. The day service center for the intervened group conducts seasonal activity programs once a month as a program outside the long-term care insurance. Users, their relatives, neighbors, children, and their parents are invited to join the program. The number of participants, especially children with parents, has increased since the study began.

Table 1

Mean age and the scores of FAST, HDS-R, Behave-AD, DAD and QOL-AD at the baseline and 12 months in the intervention and the control groups

\begin{tabular}{|c|c|c|c|c|c|c|c|c|c|}
\hline & & & Mean age & FAST & HDS-R & Behave-AD & $\overline{\mathrm{DAD}}$ & $\begin{array}{l}\text { QOL- } \\
\text { AD(P) }\end{array}$ & $\begin{array}{l}\text { QOL- } \\
\text { AD(F) }\end{array}$ \\
\hline \multirow[t]{2}{*}{ Intervention group } & Baseline & 8 & 86.5 & 4.73 & 12.18 & 12 & 52.7 & 35.27 & 31.36 \\
\hline & 12 months & & 88.1 & 5.37 & 12.75 & 9 & 43.2 & 36.25 & 32 \\
\hline \multirow[t]{2}{*}{ Control group } & Baseline & 6 & 84.5 & 5.0 & 9.37 & 4.42 & 38.2 & 32.08 & 27.92 \\
\hline & 12 months & & 85 & 5.50 & 10.33 & 44.4 & 28.8 & 30.17 & 28 \\
\hline
\end{tabular}

Table 2

Philadelphia Geriatric Center-Affect Rating Scale: The scores of the baseline and 12 months in the intervened group and the control group

\begin{tabular}{lllcccccc}
\hline & & & Pleasure & Anger & $\begin{array}{c}\text { Anxiety/ } \\
\text { Fear }\end{array}$ & $\begin{array}{c}\text { Depression/ } \\
\text { Sadness }\end{array}$ & Interest & Contentment \\
\hline \multirow{2}{*}{ Intervention group } & Baseline & 8 & 4.54 & 1.18 & 1.45 & 1.09 & 4.73 & 4.73 \\
Control group & 12 months & & 4.50 & 1.00 & 1.13 & 2.00 & 4.75 & 4.75 \\
& Baseline & 6 & 4.83 & 1.00 & 1.00 & 1.00 & 4.83 & 5.00 \\
\hline
\end{tabular}


Figure 1

Philadelphia Geriatric Center Affect Rating Scale: Pleasure (average score)

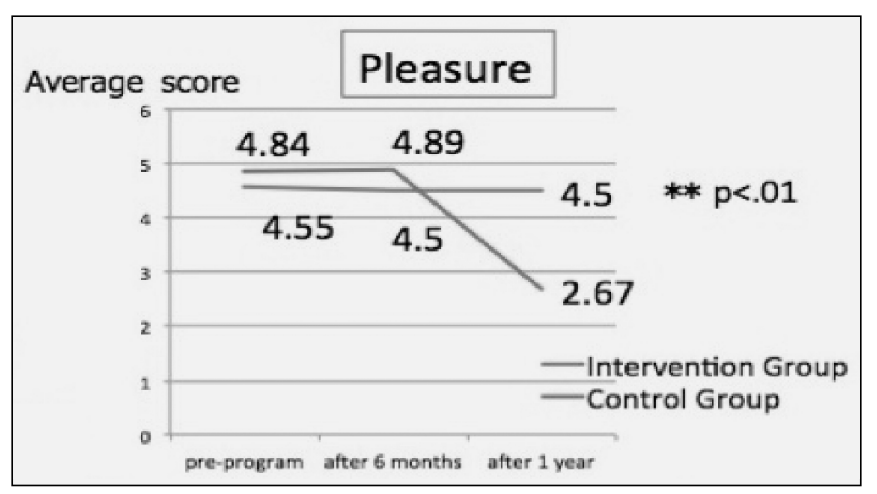

Figure 2

Philadelphia Geriatric Center Affect Rating Scale: Interest (average score)

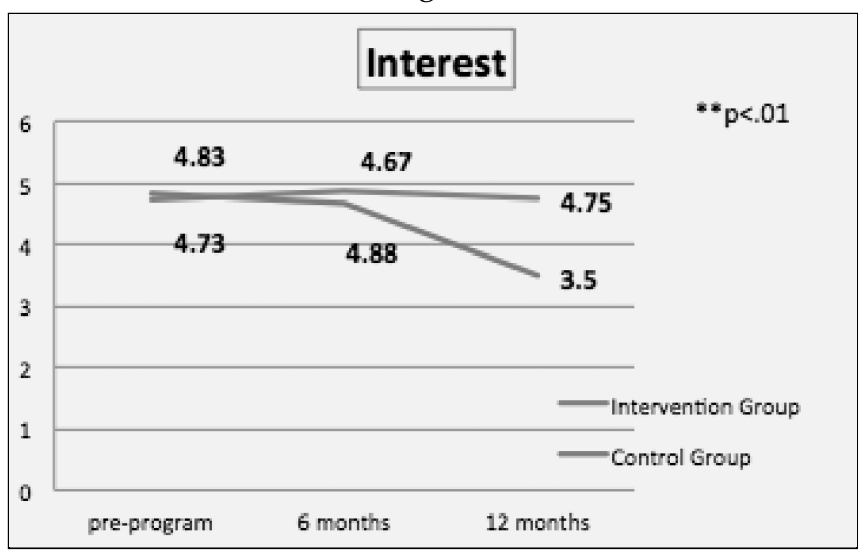

Figure 3

Philadelphia Geriatric Center Affect Rating Scale: Contentment (average score)

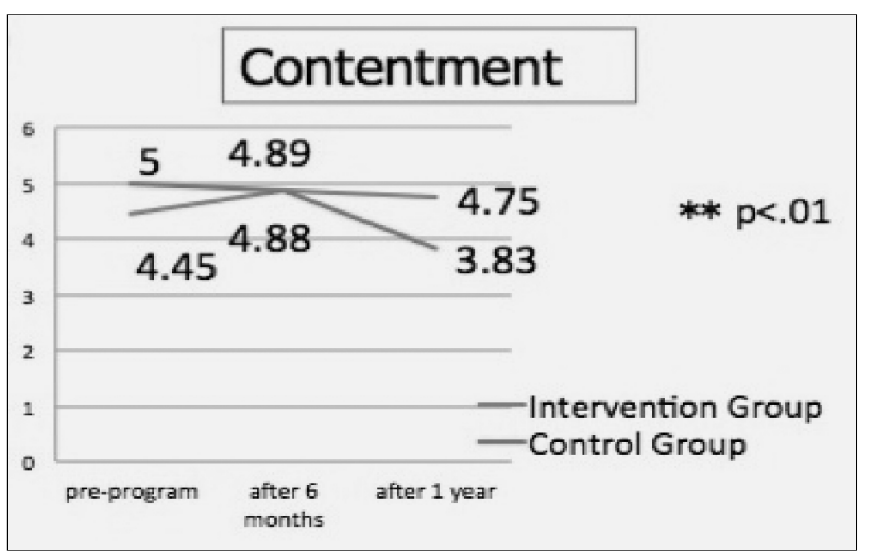

\section{Discussion}

This is the first study to report a psychosocial intervention for people with Alzheimer's disease through inter-generational cooperation with children. A lot of studies have reported on the effects of psychosocial intervention to maintain QOL of Alzheimer's sufferers or reduce carers' burden. However, there is no consensus on the psychosocial effects for Alzheimer's sufferers and their carers. In conducting the present study, one advantage is that a kindergarten is managed by the same organization managing the day service centers, vital in enabling the study.

In the results, no differences were obtained in HDS-R, DAD, Behave-AD and QOL-AD between the groups. DAD, Behave-AD and QOL-AD were evaluated based on the information from carers. So this means the program had no psychosocial effects at home for the both groups regardless of number of uses of day services. However, significant interactive effects were obtained in the items of Pleasure, Interest, and Contentment of PGC-ARS. This implies that the positive affect of the intervened group has been maintained rather than the control group while attending the sessions in the day care service. This may reduce the burden on the staff caring for Alzheimer's sufferers in the day care services.

The present results have three major limitations. The first one is the small number of subjects. Three and six subjects dropped out in the intervention and the control groups, respectively, during the twelve months. This complicates conclusions. If the subjects are limited to those with very early stage of Alzheimer's disease, the number of subjects who dropped out would fall. However, it is difficult to access the subjects with very early Alzheimer's disease under Japan's long-term care insurance. The second limitation is that the method of the study is not a randomized controlled study. However, it is not possible to assign the subjects randomly since the inter-generational cooperation in the present study is a group program, not individual cooperation. The third limitation is that the effects to the staff, the children, and their parents are not quantitatively measured, while enlightening and educational effects to the parents of the children are apparent.

\section{Conclusion}

The positive effects of PGC-ARS Pleasure, Interest, and Contentment in the intervened group were maintained, where they were not in the control group. The magnitude of the change did not influence QOL-AD at home. However, the present results may imply the reduction of burden on the cay care service staff and family carers. Also, it might be useful to educate the parents of the children, whose understanding of dementia was poor.

Acknowledgements: This study has been fully funded by the Japanese Ministry of Education, Culture, Sports, Science and Technology. The authors thank the Alzheimer's sufferers, children and their parents participating in this study.

Ethical standard: I provided a written and oral explanation of the study to the sufferers, their families, and the parents of the children, and they signed written consent forms to participate. All data was anonymized, then securely stored, 
handled, and finally disposed. All of these steps were pre-approved (No.E12HS009) by University A's Ethical Review Board.

Conflict of Interest: The authors have no conflicts of interest to disclose.

\section{References}

1. National Institute of Population and Social Security Research. Vital Statistics of Japan, 2013. Available at: http://www.ipss.go.jp/syoushika/ tohkei/Popular/Popular2013.asp?chap=0. Cited 6 January 2014

2. American Psychiatric Association. Diagnostic and Statistical Manual of Mental Disorders, 4th ed. text revised. Washington D.C.: APA; 2000.

3. Sclan SG, Reisberg B. Functional Assessment Staging (FAST) in Alzheimer's disease: reliability, validity, and ordinality. International Psychogeriatrics. 1992; 4 (03):55-69.

4. Katou S. Revising the Hasegawa simple intelligence evaluation scale (HDSR). Japanese Journal of Geriatric Psychiatry. 1991; 2:1339-1347.

5. Gelinas I, Gauthier L, McIntyre M. Development of a functional measure for persons with Alzheimer's disease. The disability assessment for dementia.
American Journal of Occupational Therapy. 1999; 53:471-481.

6. Reisberg B, Auer SR, Monteiro IM. Behavioral pathology in Alzheimer's disease (BEHAVE-AD) rating scale. International Psychogeriatrics. 1997; 8:301-308.

7. Lawton PM. Quality of life in Alzheimer's disease. Alzheimer Disease Association Disorders. 1994; 8(3):138-150.

8. Revell AJ. Quality of life in the Alzheimer's disease (QoL-AD) scale: factor solutions in non-demented elders. University Park: Pennsylvania State University; 2002. p.5. Available at: http://www.uwpsychiatry. org/sls/QOL_AD_2002.pdf. Cited January 7, 2014.

9. Phung KTT, Waldorff FB, Buss DV, et al. A three-year follow-up on the efficacy of psychosocial interventions for patients with mild dementia and their caregivers: the multicentre, rater-blinded, randomized Danish Alzheimer Intervention Study (DAISY). BMJ Open 2013;3:e003584. doi:10.1136/bmjopen-2013-003584.

10. Carrion C, Aymerich M, Bailles E, Lopes-Bermejo A. Cognitive Psychosocial Intervention in Dementia: a Systematic Review. Dementia and Geriatric Cognitive Disorders. 2013; 36: 363-375. 